\title{
Hunting Strategies with Cultivated Plants as Bait and the Prey Pathway to Animal Domestication
}

\author{
Serge Svizzero \\ Université de La Réunion, Faculté de Droit et d'Economie. 15 Avenue René Cassin, CS 92003, 97744 \\ Saint Denis Cedex 9, France \\ serge.svizzero@univ-reunion.fr
}

\begin{abstract}
For various reasons related to human diet, social prestige or cosmology, hunting - especially of large preys - has always been central in foragers' societies. When pre-Neolithic foragers have given up their nomadic way of life they have faced a sink-source problem about game procurement in the resource-catchment area around their settlements. Baiting, by mean of the cultivation of wild plants in food plots, may have help them to attract herbivores, thus improving the return of hunting activities. These foragers were also motivated by the capture of wild animals alive, in order to keep fresh meat for a while, to translocate these animals or for milk exploitation. For this capture, the use of a passive form of drive hunting seems best suited. The cultivation of food plots within the funnel and the corral might have been used to attract wild herbivores into the drive. Baiting was therefore designed either to increase the hunt or to improve the capture of large wild herbivores such as the Near-Eastern wild caprines that were later domesticated. Therefore baiting should be viewed as a hunting strategy as well as an unconscious selection mechanism since it has inadvertently contributed to the prey pathway to animal domestication.
\end{abstract}

Keywords: Neolithic revolutions, hunter-gatherers, sedentism, animal domestication, unconscious selection, large herbivores, drive hunting, Near East.

\section{INTRODUCTION}

The recent developments - based on new data and new ideas - about the transition from foraging to farming have brought new views (Price and Bar-Yosef, 2011) that provide a new picture of the socalled "Neolithic revolution". One of these novelties is that the transition from pure foraging to pure farming has been a long process and that between these two extreme methods of food procurement exists a vast middle ground. The latter has been labeled "low-level food production" by Smith (2001). It can be defined as a mixed economy (Winterhalder and Kennett, 2006) in which foraging and farming coexist in a same society and even in a same group of foragers-farmers. One consequence of the existence of this new stage in human evolution is that researchers have now to paid more attention to interactions - be they either voluntary or not - between hunting, gathering, farming and herding since they have all coexisted for a long time. More precisely we have to study whether there could have been some connections between, for instance, hunting and incipient herding, or between gathering plants and their initial cultivation.

A second novelty is that the focus of recent researches is less on the origins of agriculture than on initial domestication (of plants and animals) (Zeder, 2015). The reason is that the boundaries of an economy without or with agriculture are not well defined or blurred, especially when mixed economies are considered. However, this is not to say that initial domestication of plants or animals is easier to define (Vigne, 2011). Indeed, this new focus on initial domestication has shown that domestication is a long-term process, and that before "complete" domestication can be achieved, there exist several stages or levels of management of wild resources - such as proto-plant agriculture, the cultivation of wild plants, the management of wild herds, the taming of wild animals (Pryor, 2004; Vigne, 2011; Price and Bar-Yosef, 2011; Smith, 2007, 2009, 2011, 2012; Zeder, 2011, 2012, 2015). The question is thus how and why the domestication process has evolved from one of these stages to the next one.

Both new views are the result of several components. The latter include new data provided by new archaeological excavations, the (re)-examination of archaeological records thanks to new techniques, 
such as, for instance, DNA analysis. Among these components is also a new conceptual approach, Niche Construction Theory (NCT) (Odling-Smee et al., 2003). Its aim is the study of human/environment interaction and it is derived from the developments of Behavioral Ecology. NCT was developed directly out of macroevolutionary theory in the mid-1980s. Contrary to the Darwinian and neo-Darwinian approaches, NCT centers on the issues of directionality and intent in evolution. In other words, adaptation is considered as being symmetrical, i.e. human adapt to environmental changes (as in the Darwinian approach) but human also adapt the environment according to their needs. Thereby Odling-Smee et al. (2003) argue that niche construction is universal and should be regarded, alongside natural selection, as a second major participant in evolution. During the last decades NCT has been extensively used by scholars - especially those focusing on the prehistoric period - in order to describe human behavior such as foraging or farming (Rowley-Conwy and Layton, 2011), its impact on the environment and biodiversity (Smith and Zeder, 2013; Boivin et al, 2016) and several episodes of human evolution such as the Neolithic revolution (Smith, 2007, 2011, 2012, 2015; Zeder, 2009, 2011, 2015) and its spread (McClure, 2015; Boivin et al, 2016).

One interesting and apparently paradoxical aspect of NCT is provided by its description of initial domestication. Indeed, on the one hand the core principle of NCT is human intention, i.e. the deliberate engineered enhancement of ecosystems. As stated by Smith (2012), niche construction by small-scale societies - such as pre-Neolithic bands of hunter-gatherers - is in large measure designed to increase the relative abundance and reliability of preferred wild species of plants and animals within resource-catchment areas, and to reduce the amount of time and energy required to harvest them. On the other hand, most authors of recent publications - if not all - describe the initial domestication of plants and animals as a non intentional or unconscious outcome (Vigne, 2011; Larson et al., 2014; Larson and Fuller, 2014; Rowley-Conwy and Layton, 2011; Zeder, 2012, 2015). Such vision is not new (Larson et al., 2014: 6142). Indeed, Charles Darwin was the first to explicitly articulate the difference between conscious selection during domestication, in which humans directly select for desirable traits (called by Darwin "methodical" selection), versus unconscious selection, where traits evolve as a by-product of growth and natural selection in field environments, or from selection on other traits. In others words, it is now commonly agreed that pre-Neolithic foragers have deliberately managed their environment to satisfy their needs and that such management has inadvertently led to the domestication of plants and animals. Domestication is thus not due to some hazard, but is considered as an unexpected consequence of foragers' actions. Given this common view about the origin of domestication, one challenge for scholars is then to explain what are the mechanisms underlying this unconscious selection, where they come from and how they might have contributed to plants and animals domestication. This is what the presented paper aims to do by focusing on the initial domestication of some large herbivores, more precisely goat and sheep.

Concerning these large herbivores, it is assumed in the academic literature that, in response to various stimuli such as human population pressure or human's sedentism, the preys targeted by hunters have progressively changed, from old animal to prime-adult, and to young animal. More importantly, this selective hunting strategy - initially designed to increase prey availability - has inadvertently led to another outcome, i.e. the reduction of the wariness and the reactivity of these anthropophobic animals, and therefore it has facilitated the evolution along "stages" of the prey pathway to animal domestication. Even though such evolution is likely to have occurred, the academic literature is quite evasive about its modalities, as illustrated by the following citations :

Zeder (2009: 38): "It seems that in certain cases and with certain species, efforts at enhancing returns from wild herds eventually led to full-scale domestication (i.e., sheep, goats, pigs, and cattle) (...)."

Zeder (2012: 174) : "Over time and with responsive species (...), these game-management strategies developed into herd management strategies that included the sustained multigenerational control over the animals' movement, feeding, and reproduction characteristic of the domestic relationship."

Larson and Fuller (2014: 119), "Instead, humans likely altered their hunting strategies to maximize the availability of the prey. In so doing, the selection pressures for traits such as docility would have been significant as people moved from game management to herd management, to more complete control over the animals' diet and reproduction."

Thus our purpose is to identify another mechanism - in addition to selective hunting - used by hunters to increase the availability of large herbivores considered as preys which could have inadvertently 
contributed to their domestication. Since such mechanism was implemented by hunters, we have to search it among the various hunting strategies that pre-Neolithic hunters could have used. It appears that baiting, i.e. the use of food ${ }^{1}$ to attract targeted animals, has been an hunting strategy in all epochs (Leopold, 1933). Even in the twentieth-one century, the focus on fine-scale practices and the desire for instant gratification when managing wildlife habitats persist (see e.g. Putman and Staines, 2004). Therefore we demonstrate in the sequel of the present paper, that baiting was a feasible strategy for pre-Neolithic hunters, why the latter could have used such strategy, and how it might have contributed to the domestication of Near-Eastern wild caprines. ${ }^{2}$

\section{The Primacy of Hunting In Foraging Societies}

Before we turn to animal domestication we have to explain our focus on the role of baiting. Indeed, baiting is hardly considered in the academic literature about the Neolithic revolution. We believe that is it so because the transition to farming is most of the time considered from farmers' point of view. For us, since domestication is an unexpected outcome of wild resources management, then the transition from foraging to farming must be considered from the point of view of those who managed these wild resources, i.e. from hunters' point of view. Therefore we have to recall that even though foraging activities and societies were very diverse (Kelly, 1995), hunting was and is central in all foraging societies, from the far past to the most recent ones. Three evidences support this claim.

First, hunter-gatherers have always favored animal food in their diet and of course animals have first to be hunted (except when meat comes from scavenging). As demonstrated by Cordain et al. (2000: 682 ), whenever ${ }^{3}$ and wherever it was ecologically possible, hunter-gatherers have always consumed high amounts (45-65\% of energy) of animal food. Most (73\%) of the worldwide hunter-gatherer societies derived $>50 \%$ (56-65\% of energy) of their subsistence from animal foods, whereas only $14 \%$ of these societies derived $>50 \%$ (56-65\% of energy) of their subsistence from gathered plant foods. In other words, the biological goal of foragers leads them to consider hunting as a crucial economic activity.

Second, in all societies (of foragers, farmers or else) and at least until the last decades (of the twentieth century), hunting has always been associated with social competition and prestige. This was especially true for pre-Neolithic foragers since hunting was the only mean to get animal food. We recall that even though foraging societies are considered as egalitarian, there was some degree of labor division and specialization based on gender: the men hunted and the women gathered. Hunting was therefore a male activity and even in a egalitarian society a good hunter had special advantages such as more mating. Most hunter-gatherers prefer to hunt for big game, even though big game is treated as common property of the band regardless of who kills it. Social approval, prestige, and competition for wives seem to be adequate incentives to get males to hunt for the whole band (Hawkes, 2001). For instance, Hawkes (1991) uses the Ache people of Paraguay as evidence for the "Show-off hypothesis", i.e. the concept that more successful men have better mate options.

Third, the central importance of hunting in foragers' society is also confirmed by the ubiquitous presence of animals and hunting scenes in parietal $\operatorname{art}^{4}$ of the upper Palaeolithic period (see e.g. Clottes and Lewis-Williams, 1998) while plants or fish are absent of cultural manifestations until the Neolithic period. This ubiquitous presence of animals in hunters' values and beliefs confirms that hunting was central in foragers' societies also for cosmological reasons.

Finally, and as pointed out by Frison (1998: 14578), despite the abundance of animal remains that were hunted during the prehistoric period, their taphonomic analysis tells us very little about the actual procurement strategies involved. This has led many archaeologists to have relied on rock art of hunting episodes. However the latter violate many rules of intelligent hunting and thus lead to inaccurate and false impressions of predator-prey relationships. Therefore, there is no reason to $a$ priori exclude, among the possible prehistoric hunting strategies, baiting - and more precisely the

\footnotetext{
${ }^{1}$ We restrict our analysis to the use of food even though baiting also includes the use of decoys, lures or scents to attract animals.

2 The tribe Caprini includes the Genus Capra as well as the Genus Ovis.

3 I.e. even from the so-called "Broad Spectrum Revolution" featuring the Mesolithic period during which foragers have diversified their diet and especially increased their consumption of plants and marine resources (fish, shellfish).

${ }^{4}$ Defined as the non-mobile works that include paintings, drawings, engravings, and reliefs on cave walls.
}

International Journal of Research in Sociology and Anthropology (IJRSA) Page 55 
cultivation of food plots - in order to attract wild game, either to kill them or to capture them alive into corrals.

\section{InItial Domestication as an InADVERTENT ConSEQuence of WiLd Resources MANAGEMENT}

Even though the present paper focuses on the domestication of large herbivores, it is worth noting first that in the academic literature the domestication of cereals is also considered as an unexpected outcome of the management their wild progenitors. According to many authors (Larson et al., 2014; Larson and Fuller, 2014; Rowley-Conwy and Layton, 2011; Zeder, 2009: 29-30) and for the domestication of cereals (wheat, barley and rice), it is assumed that the unconscious selection mechanism comes from the harvest method used by foragers. Indeed, most wild cereals are characterized by shattering ${ }^{5}$ seeds, a natural feature which favors their reproduction. The harvest of such cereals is difficult since seeds readily fall off the stalk. To gather these wild cereals the foragers have used an harvest technique called the "swinging basket" in which they have had to beat the seed heads into baskets (Harlan, 1992). The problem is that such solution requires much effort and, moreover it requires the constant vigilance as the field ripens. Thus, being motivated by the reduction of their effort, the foragers have introduced another harvesting technique, the use of sickle leading to stalk-harvesting rather than seed-harvesting. This new harvesting method has led to the unconscious selection of non shattering seeds, and after a long period, 2,000 to 4,000 years (Larson et al., 2014 : 6142), the non shattering spikelet phenotype was fixed, a key indicator of cereal domestication. Indeed, with the basket swinging technique, the non shattering seeds - which in the wild constitute a low percentage of a cereal population - were hardly harvested. By contrast, with the use of sickle, the ears with seeds retention were harvested on a priority basis. Therefore their percentage of the total seeds harvested has progressively increased, and so it was for the seeds stored and sown subsequently. After 2 to 4 millennia of such unconscious harvest of wild cereals characterized by an increasing percentage of ears with seeds retention, all the cereals harvested and cultivated have been characterized by non shattering seeds, i.e. these cereals were domesticated inadvertently. It should be noted that such outcome clearly corresponds to domestication since with seeds retention the cereals reproduction cannot be achieved without human intervention.

\section{The Three Pathways to Animal Domestication}

Concerning animals domestication, the picture is more complex than for plants domestication. This is probably because the plants/humans relationships were - in the prehistoric period -mainly ${ }^{6}$ oriented according to their contribution to human diet. Human-animal relationships are more diverse, even during the prehistoric period, and it is now agreed that there were three relationships, leading to three different pathways to animal domestication (Zeder, 2012; Larson and Fuller, 2014). It is therefore interesting to study each of these three pathways to identify what were the unconscious selection methods - if any - that have led to animal domestication. Chronologically, the animals that were lately domesticated (horse, donkey, camel...) have attracted human attention not for their possible contribution to human diet, but for some services they can provide, for instance as beasts of burden. Here the domestication was clearly conscious and thus it is labeled as the "direct pathway". The first animal ever domesticated was the dog. Gray wolves, the source species, are asserted to have first evolved into dogs in East Asia c. 15,000 BP, during the latter stages of the most recent Ice Age (Savolainen et al., 2002). For the dogs, as well as for other animals domesticated later (cat, chicken...), the domestication was unconscious. Indeed these animals were attracted by human camps (of mobile foragers) and later by their settlement (of sedentarized foragers) around which human refuse and commensal animals (e.g. small rodents) were present. Thus the unconscious selection mechanism that has led to this "commensal pathway" could be defined as "inadvertent baiting".

The third pathway is about animals that have been domesticated but that initially were human's preys. They correspond to what nowadays we call "farm animals" and mainly include large herbivore (goat, sheep, cattle..), the latter being the four domesticated animals (when pig is included) on which the Neolithic revolution has been built. They have been domesticated initially for their primary products

\footnotetext{
${ }^{5}$ Such feature is also called dehiscent or without seed retention. Non shattering occurs as a rare mutant in wild cereal stands.

${ }^{6}$ However there exist some plants managed for purposes others than their contribution to human diet, for instance flax was used for its fibers - more than for its seeds.
} 
(meat, blood, bones, hide) and later ${ }^{7}$ for their secondary products (milk, wool, traction) (Sherratt, 1983). Initially these have animals were preys, i.e. they were wild, free-living in the nature and hunted to be culled immediately and finally they have been domesticated, i.e. have lived in an anthropogenic environment. Thus their domestication involves some unconscious selection mechanisms. About the latter, and until now, the academic literature has focused its attention on selective hunting.

\section{Selective Hunting And Game Management}

It is now agreed that the herbivores (goat, sheep and cattle) that were first domesticated were initially considered by hunters as preys (Zeder 2012), i.e. these animals were primarily hunted for their meat. For a long time - let us say before the Holocene - this hunt was not selective, i.e. all animals (young, adult, old) of any species were hunted. Probably, and according to optimal foraging theory (Winterhalder and Kennett, 2006; Gremillion et al., 2014) - hunters tried to maximize the net energy of the hunt - and thus the older animals were mainly culled because they were easier to hunt. Progressively, the hunt intensified and became more selective, targeting first the prime-age adult which usually are the meatiest. Such intensification and specialization derives from various reasons. The Pleistocene-Holocene transition, its climate change and the resulting dense ecosystems provided more vegetation and thus animals proliferated, including the herds of wild herbivores. Moreover, the improvement of hunters' weaponry (the introduction and the subsequent improvement of the bow and arrows) allowed them to reach, silently and faster than before, targets on longer distance. Such intensive hunt has inevitably led to overexploitation - and possibly local extirpation - of some animal species, especially large herbivores since they have already been highly prized, for their meat as well as for the prestige (Hawkes, 1991) they provide to their hunters.

At the beginning of the Early Holocene - about 11,700 years ago - and in order to avoid the extirpation of their favorite game, hunters have started to manage the wild herbivores by mean of a hunting strategy designed to increase prey availability. For such purpose they have adopted a strategy based on a "new" selective hunting since now the latter had two targets. First, the hunters culled preferentially some animals according to their behavior. The animals with wariness and high reactivity with respect to human presence were preferred preys and it was mainly adult males. In doing so, the animals remaining in the herd were more docile and thus the hunters had to spend less energy during their subsequent hunts. Once again, such human behavior is perfectly consistent with optimal foraging theory. The second preferred target of this selective hunting was young animals, especially young males (Atici, 2009). Indeed, hunters had noticed that by culling these young animals, the remaining females were instinctively "forced" to breed at an higher rate (Rowley-Conwy and Layton, 2011). Indeed, species evolving in unstable or unpredictable environments - e.g. due to overhunting - adopt an evolutionary strategy called " $r$-selection". These $r$-selected species place an emphasis on a high growth rate, produce many offspring, each of which has a relatively low probability of surviving to adulthood. Thus, with such reproductive behavior, the stock of wild animals available for hunting was greater than before. It should be noted that the selective hunting based on the two targets previously described - was a game-management strategy leading to an outcome very similar to what herders did later with domesticated animals, i.e. it led to a large herd of docile animals, with few adult males, mainly reproductive females, and some young animals (mainly females).

\section{Settled Foragers and Human-Animal Proximity}

Even though the selective hunting has led to more docile animals, the management of a herd of such animals was probably not easy, because these animals were still wild. One should also note that there is a long delay between unequivocal signs of animal management and the display of clear morphological manifestations of animal domestication (a period of about 2000 years in sheep and goats) (Zeder, 2009: 37).

\section{From Management to Taming}

\footnotetext{
${ }^{7}$ The delay between the focus on primary and then on secondary products is however in the academic literature a matter of debate and controversy (Helmer and Vigne 2007; Marciniak, 2011).
} 
The next stage in the management process of animals is taming. When taming is achieved, it means that the distance flight of animals ${ }^{8}$ is very short or even nil, i.e. that animals are no more scared by human's presence. To achieve such goal it is necessary that animals and humans live in close proximity, permanently or so. It is for such reason that, for instance, reindeer herders have to be nomad. Indeed, the reindeer (Rangifer tarandus) is a migratory species and then its taming requires the presence of humans in close contact with the herd along the migratory road.

The progenitors of the herbivores that were initially domesticated in the Near East are the bezoar or wild goat (Capra aegagrus) and the mouflon or wild sheep (Ovis orientalis). Both species are highly social and gregarious but they are not migratory. As described previously, during the Epipalaeolithic period (from ca. 20,000 to 14,000 calibrated years BP) in the Taurus Mountains both species have been hunted intensively, and then selectively (Atici, 2009). Since they are not migratory species their domestication has been achieved in their natural habitat (Zeder, 2005). Before they were domesticated, they were managed and then tamed, and given our previous argument, this has required proximity between these species and the hunters. Such requirement has led mobile foragers to give up their nomadic way of life in order to establish - in the area where these herds were living - semi permanent and later permanent settlements.

\section{Sedentism and Sink-Source Dynamic}

A recurrent problem for foragers who settle down, is that now their foraging activities are delimited by a resource catchment area. Beyond this area, foraging is too costly, except if it is a very rare event. In the area, the foraging pressure is maximum at the center, i.e. close to human settlement, and it decreases from the center to its external boundary. This pressure induces a fundamental problem for hunting, the so-called "sink-source" dynamic associated with game. In fact, the composition and spatial arrangement of habitat patches in the landscape often have a strong influence on the population dynamics of species. One of the consequences of landscape complexity can be the source-sink dynamic produced when individuals in the same population occupy habitat patches of different qualities. Productive patches, where reproduction exceeds mortality, act as sources of individuals that disperse to less productive sink patches. Subpopulations in sinks would go extinct without dispersers from sources.

The source-sink dynamics may be explained by different reasons: it may result either from natural heterogeneity in habitat quality, or heterogeneity produced indirectly by human alteration of habitats, or by hunting pressure. Concerning hunting, it is usually concentrated in areas that are more accessible to humans - the resource catchment area - and thus hunting may create spatial differences in mortality for game species and influence their population dynamics at a landscape scale. In other words, the resource catchment area around the settlement of sedentarized foragers is likely leading for hunted large herbivores - to a sink-source dynamic. The resource catchment area becomes the sink and beyond this area is the source. However, intensively hunted populations of wild ungulates with high dispersal ability may also persist in the sink zone as a result of immigration from the source, namely the unhunted area (Delibes et al., 2001). The question is therefore what may explain such immigration, i.e. for what reasons wild ungulates remain in the catchment area - the sink - where their mortality induced by hunting is very high? The answer is that they are attracted, for some reasons, into this area.

In other words, since the pressure of hunting is high in the resource catchment area, most animals are rapidly culled, and the others - especially large herbivores which are highly mobile - leave the area. Therefore, and even though the herd of wild herbivores was managed and docile, it is less likely that it voluntarily remained around human settlements, and thus in close contact with humans. In other words, for sedentarized hunters, the taming of wild animals required some management strategy beyond selective hunting. Indeed, hunters have had to attract these wild herbivores around their settlement in order to maintain a high return of their hunting activities.

\section{The Attractiveness of the Resource Catchment Area: From Vegetation MANAGEMENT TO BAITING}

\footnotetext{
${ }^{8}$ It is also defined as the critical distance for an animal, i.e. the distance a human or an aggressor animal has to approach in order to trigger a defensive response of the first animal.
} 
As highlighted by niche construction theory (Odling-Smee et al., 2003; Smith 2007, 2012), preNeolithic foragers have practiced an integrated overall strategy of restructuring vegetation communities in ways that enhanced and expanded the habitats of many important food sources.

\section{Vegetation Clearance, Open-Spaces and Rich Edge Areas}

According to such perspective, hunting and forest fragmentation are correlated as open-space promote sustained hunting. Indeed, most large game (deer, elk...) have an important part of their diet which consists of the twigs, shoots, and leaves of low growing shrubs and bushes. Therefore, their population densities are low in climax forest situations where a closed canopy has been established, and are high in early successional situations that have small areas of varying types, producing maximum edge areas between habitat zones. As a result, human clearance of vegetation would actually have improved their habitat and increased carrying capacity levels. We have various evidence that the niche construction efforts of small-scale human societies may modify vegetation communities in ways that result in the capture of a larger percentage of an ecosystem's total biotic energy. For instance Smith (2009) provides explanation on how the white-tailed deer (Odocoileus virginianus) was managed by hunters in the Mississippi River Valley corridor.

Pollen and phytolith studies provide evidence of forest clearing, especially by mean of fire. From a long time ago human have used fire to transform their landscape, having noticed that fire cleared older vegetation and encouraged a host of quick-colonizing grasses and shrubs-many of them bearing desired fruits, berries, and nuts. Moreover the ash from the burning also served as a fertilizer. They especially have noticed that fire later stimulated the browse that attracted game. In fact fire acts as a powerful magnet, bringing a suite of desirable flora and fauna closer to human's settlement, the resulting concentration of foodstuffs and game leading to the reduction, in proportion, of the necessary radius of hunting and gathering.

\section{Baiting to Attract Wild Game}

Beyond large herbivores, many wildlife populations aggregate in small spatial areas in response to human modifications of the environment (Leopold, 1933). A good example of such a modification is the placement of supplemental feed, either via bait, or natural or artificial forage within the native habitat of species. Even nowadays supplemental feed is provided to wildlife across numerous parts of the world to address various ecological and socio-economic purposes such as alleviating winter mortality, increasing reproductive success, controlling wildlife damage to crops and the environment, reducing wildlife-vehicle collisions, controlling animal migration routes, and optimizing hunting and tourism opportunities (Putman and Staines, 2004). Supplemental feeding and baiting have close connections but they have different objectives. Indeed, supplemental feeding can be defined as the provision of food by humans with the intention to enhance some specific physical characteristics of individuals or to benefit population dynamics, e.g. increased antler growth, fecundity, and survival. Baiting of wildlife involves the purposeful placement of natural or artificial food resources in the environment to manipulate the behavior of wild species so as to attract and/or retain them in an area.

In the pre-Neolithic period, baiting was likely used for the purposes of either attracting wildlife to a specific location to enhance hunter harvest, or capturing wildlife for various purposes including animal relocation. Since sedentarized pre-Neolithic foragers have managed the landscape around their settlement in order to attract game, it is possible to consider what kind of management they have used. Indeed, the creation of open-spaces and glades was a first step and the subsequent step was surely to improve the attractiveness of these open-spaces by mean of baiting. For such purpose, the foragers have had to foster the growth of the plants preferred by the large herbivores they were hunting.

\section{BAITING AND CUltivation}

Such proto-plant-production places a great emphasis on managing the environment for plant production, rather than nurturing the crops or deliberate manipulation of the genetic materials of the plants. In addition to "fire-stick agriculture" described above, several types of proto-agriculture deserve mention, including watering fields, soil aeration, removing weeds and other undesirable plants. We may also include some forms of cultivation ${ }^{9}$ such as sowing seeds and transplanting

\footnotetext{
${ }^{9}$ According to Price and Bar-Yosef (2011: S165) we differentiate "cultivation" (defined as intentional preparation of the soil for planting wild or domesticated plants) and "domestication" (defined as morphological or genetic changes in plant and animal species).
} 
various plants and trees. Indeed, as supported by archaeological evidence, many sites of early agriculture were settings where crops could be sown with a minimum of labor. The most striking case is what is known as "flood-retreat" agriculture or semi-sowing, i.e. broadcasting seed on the soft and fertile silt left on a riverbank by the receding annual floods. The transplantation of plants and their subsequent cultivation - even on a large scale - is clearly attested in various prehistoric contexts, e.g. it concerns agave in the American southwest (Smith, 2011: 843). Similarly the Kumeyaay tribe on the California-Mexico border transplanted various plants and trees (Smith, 1995).

Both "primitive" forms of cultivation, i.e. sowing or broadcasting seeds and plants transplantation, could be handled properly by pre-Neolithic foragers. Indeed, as pointed out by Flannery (1969): "We know of no human group on earth so primitive that they are ignorant of the connections between plants and the seeds from which they grow...". In fact, it is well known that small-scale human societies develop and maintain, in the form of shared oral traditions, beliefs, myths, and stories, huge amounts of information about their environment -the so-called traditional ecological knowledge - and this information is passed down from generation to generation (Smith, 2012). What is new in the present paper is that we establish a close connection between initial cultivation and hunting. Indeed, in our approach cultivation of some plants is undertaken as part of the baiting strategy which aims at attracting more game close to human settlement. In others words, cultivation is considered as an input of the hunting process.

\section{Wild Crops Cultivation in Food Plots}

It is likely that wild cereals and pulses were among the plants cultivated in the food plots and used for baiting. Two reasons support such assertion.

First, when foragers have had to decide which plants they should use for baiting, they have likely chosen plants that grow easily. Wild cereals and pulses were perfect candidates for such purpose. Indeed, plants with seeds, such as cereals and pulses, are quite easy to cultivate because their seeds (in few quantity) can be transported, stored and sowed without too much effort. To some extent their transplantation is also possible; depending on the cereal considered, the number of primary roots varies - e.g. from one in the warm climate cereals maize, rice, and sorghum, to six or seven in the cool climate cereals, triticale and wheat - and a complex root system architecture - rather than a taproot facilitates transplantation.

Second, when foragers have had to decide which plants they should use for baiting, they have likely chosen plants that were attractive for a broad range of wild species, including ungulates, hares and birds. As demonstrated by the "garden hunting model ${ }^{10 "}$ initially introduced by Linares (1976), game is attracted by cultivated fields despite human presence. The cultivation of food plots including cereals, pulses or legumes was thus a real magnet for wild game, including the preferred target of hunters, i.e. large herbivores. Even nowadays, several studies in the world are about damages to agriculture, and more specifically on the damages causes by large herbivores (deer, elk...). All studies show that wild herbivores are clearly attracted by crops and that most damage by deer are to cereals (see e.g. Wilson et al., 2009).

\section{The Exploitation of Near-Eastern Wild Plants and Animals: Archaeological Evidence about Dates and Places}

In addition to the two previous reasons, it should be noted that while in 1995 there appeared to have been at least a 1,500-year gap between plant and animal domestication (Bar-Yosef and Meadows, 1995), it now seems that both occurred at roughly the same time (Zeder, 2011; Vigne, 2011: 6). Moreover, the initial management of morphologically wild future plant and animal domesticates is now assumed to have occurred to at least $11,500 \mathrm{cal} \mathrm{BP}$, if not earlier (Zeder, 2011). In others words, and according to Larson et al. (2014: 6141, fig 2) the exploitation before domestication of some wild plants (wheat, barley, lentil) and some wild animals (sheep, goat) have occurred at the same time. Therefore, there is no reason to exclude $a$ priori the fact that these exploitations of wild plants and wild animals were connected.

\footnotetext{
${ }^{10}$ According to Stahl (2014), "garden hunting" refers to subsistence exploitation of local wild animals that are either passively or intentionally - attracted to the concentrated foraging opportunities provided in horticultural settings throughout the tropics.
} 
Another argument supporting our view is provided by the place(s) where cultivation and domestication of cereals is (are) assumed to have started. Indeed, it has long been claimed that plant domestication occurred rapidly in a single restricted sub-section of the Near Eastern Fertile Crescent, namely in Abu Hureyra. Based on genetic studies, the most recent publications have demonstrated that such "core area" did not exist since the appearance of early cultivars and domesticates was spread piecemeal around the Near East (Fuller, Willcox \& Allaby, 2011). Since multiple geographical origins of plants cultivation and domestication are possible, one may surmise that some of these locations were close to - or even within - the Taurus and the Zagros Mountains where wild caprines lived and were initially managed.

\section{The CaPture of Wild Ungulates: The Goals}

In the previous sections of the present paper we have assumed that the human-animal relationship was fully described by a predator-prey dynamic. Indeed, foragers' objective was to hunt wild game until it was killed and subsequently consumed. Since we have restricted our analysis to some ungulates namely the wild goat and the wild sheep - it is possible to consider that foragers' goal was to hunt wild game but without killing it and instead to keep wild animals in captivity. In fact the capture of wild animals may be explained by three different reasons. They are presented below, according to their respective chronological relevance.

\section{Delayed Slaughtering}

When an animal is hunted and killed, its meat must be consumed rapidly (say few days) - especially in hot or temperate climates - otherwise the meat get rotten. A solution to preserve the meat on a longer period is to dry it, by smoking it or using salt. The problem is that such food processing technique is costly and risky. Indeed the drying process is long, its requires scarce inputs such as salt, and a lot of attention to keep the meat away from predators (rodents, birds, carnivores...) during the processing and also when the meat is dried and stored. Moreover, such process is not well suited for mobile foragers who have to carry on their back all their possessions. Therefore, another solution to get fresh meat on a regularly basis was to hunt almost every day. Of course such strategy was also costly because it required daily efforts for hunters and, in addition, their hunt was not necessarily always successful.

Thus, drying and storing meat as well as hunting every day or so were two costly strategies for preNeolithic foragers. It therefore seems quite logical that to overcome such difficulties - and even before the Holocene - hunters have tried to capture wild animals to keep them in captivity for a while. In doing so, they were able to have, from a unique hunt, fresh meat during several days since they slaughtered day after day some of the animals they had caught. It should be noted that such situations have nothing to do with any management of wild animals and a fortiori with taming. Indeed, the hunters did not have to take care of the captured animals since their purpose was simply to delay their culling. The unique requirement for hunters was to keep these wild animals in captivity, by means of tethering or penning them for instance.

\section{Animals Transport and Relocation}

Beginning in the early 1990s a number of sites have been discovered and excavated on Cyprus that have radically transformed our understanding of Neolithic emergence in the Mediterranean Basin. Indeed, as an island - isolated of mainland - its upper Pleistocene terrestrial mammalian fauna was reduced to only four or five endemic species. Around 10,500-9,000 B.P., pioneers probably coming from the Northeastern Levant, and traveling by boat, have introduced into Cyprus mainland animals (Zeder, 2008). These include wild game (fallow deer, fox) and early domesticates fauna (dog, sheep, cattle). In addition to the previous taxa, goat and pig were also present but all the goats and approximately half of the suids were wild/feral and therefore were obtained by hunting (Vigne et al., 2011).

In fact such transportation and relocation of domesticated animals is not an isolated event, but it is well documented for Cyprus. For instance, even before the colonization of Cyprus, i.e. shortly after the early PPNB, early domestic ungulates were transported far from their areas of origin - the Taurus mountains - toward the south, to the Damascus region (Vigne, 2011). Later, all the coasts and the islands of the Mediterranean basin have been colonized in a way similar to that of Cyprus (Zeder, 2008). What is more interesting given our aim is that such transportation and relocation have also 
concerned wild animals, or more precisely wild animals that were "managed" and thus before morphological modifications due to their domestication were detected. For instance, Naderi et al. (2008) have studied the phylogeographic structure of the bezoar and showed that it is weak compared to other wild ungulates. The authors have concluded - because such mixing of haplotypes is very unusual in natural populations - that the most likely explanation for this mixing in bezoars is that humans translocated many animals in the past. In other words, their study consider as a possibility the management of wild flocks.

It should be noted that all these transportations - especially when undertaken by boat -necessarily entailed acclimatization of the animals - either wild and managed or early domesticates - and brought about a further level of animal control. Of course, a prerequisite for such control of wild animals is that they were initially captured.

\section{Milk Exploitation}

In the early 1980s a new concept called "Secondary Products Revolution" (SPR) has been introduced in archaeology (Sherratt, 1983). The main idea was in fact twofold. On the one hand, it was assumed that domestic animals were initially used for their primary products rather than any of their other uses. Primary animal products are defined as those which can be extracted only once in the lifetime of the animal, upon its death, and include meat, hide, blood and bone. On the other hand, this previous mode of animals exploitation was later replaced by a more diversified exploitation for their secondary products, ${ }^{11}$ such as milk, wool and textiles, and applications, such as traction power or transport. Thus, Sherratt (1983) argued that exploitation of secondary products appeared long after animal domestication, and that it should be considered as a consequence, not a cause, of the domestication. Subsequent researches have systematically used faunal data to test Sherratt's hypothesis about the introduction of secondary products in later phases of the Neolithic. These researches have led to a more balanced vision about the introduction of SPR, especially about milk and dairy products.

First it has been demonstrated that the strict association of the SPR with the late Neolithic phase was a strong assumption. Indeed, the changes that might be linked with the Secondary Products Revolution are by no means associated with a single century or millennium and emerged in different periods across the Near-East (Marciniak, 2011).

Second, by interpreting slaughtering age profiles which reflect animal management strategies, Helmer and Vigne (2007) provide clear evidence for milk exploitation of sheep and goats as early as the first advances of the Neolithic in the Near East. Since dairy products were already part of the diet at the very beginning of the Neolithic process, it therefore seems likely that they should have played a role in the earliest Near Eastern domestication processes.

From the previous conclusion one may even surmise that milk exploitation has occurred before the Early Neolithic, i.e. that milk was derived from wild animals. Such claimed can be challenged, as did by Larson and Fuller (2014: 124) because milk is metabolically expensive and, under wild conditions without the aid of human food provision, likely to be limited in production. However, it is well known that Neolithic people continued to obtain most of their meat diet from hunting during the thousand years after the appearance of domestic ungulates. In other words, whether Neolithisation was not a way to increase meat supply, one may wonder for what purpose ungulates have been initially domesticated. One explanation could be milk exploitation, given that its symbolic value as a figure of the maternal link should have already been high (Vigne, 2011: 178). One should note that since milk exploitation is only available from captive animals, it implies - if, as suggested previously, it has existed before the Neolithic period - as a prerequisite the capture of wild animals.

\section{The Capture of Wild Ungulates: The Methods}

Whatever the goal - among the three mentioned above - explaining why pre-Neolithic hunters have kept in captivity wild game (we focus on goat and sheep), they have had first to capture these animals. They also have had to take care of these animals, during their capture and also during the period these animals were kept in captivity. The previous point implies that the techniques used by hunters for the capture of wild game should not have negative impacts on the latter, such as body injuries or excessive stress. Even nowadays, the capture of wild animals exists since, for instance, much research

\footnotetext{
${ }^{11}$ By contrast, secondary animal products can be exploited without slaughtering animals, and the same animal can be repeatedly exploited in the course of its lifetime.
} 
on wild mammals requires trapping and marking animals. It is thus possible to infer, from current recommendations for trapping and marking mammals (Powell and Proulx, 2003) - minimizing unwanted, negative impacts on the individual mammals and populations - which techniques were likely used by pre-Neolithic hunters. Capture devices classified as live traps are numerous and diverse. However, most of them were not well suited for the capture of large herbivores. Indeed, pitfalls traps and snares imply injuries on animal's body. Cage traps are appropriate but they were not easy to build by prehistoric hunters and each capture is restricted to a unique animal. In fact drive corral, i.e. an enclosure and a funnel fence that directs animals into the corral, are well adapted for the capture of large herbivores since they reduce injuries and mortality, and can capture larger numbers of animals at one time (Powell and Proulx, 2003: 269).

Building and using a drive corral for the capture of wild animals is a technique that pre-Neolithic hunters were mastering since for millennia one of their hunting strategies was driving, i.e. the herding of wild animals in a particular direction, ending with the culling of these animals.

\section{Pedestrian Game-Drive Hunting}

Driving is a form of hunting strategy which was used even during the Pleistocene. It consists in channeling and constraining animals' movement to allow for easier harvesting. The simplest structure of a drive corral has a triangular shape, consisting of two long arms or wings (built of stones, wood or brush) and arranged in a V-shape, like a funnel, ending as a corral. Hunters pushed the game between the arms, trapping then the animals into the end of the structure. It is usually considered that animals were slaughtered "en masse". In the Levant for instance, such stone structures, called "desert kites", are numerous. They have been used for mass harvesting of wild ungulates and have likely contributed (in the post Neolithic period ${ }^{12}$ ) to the extirpation of some species, such as the Persian gazelle (Gazella subgutturosa), (Bar-Oz et al., 2011). Thus, hunters have built elaborate drive structures, using stones and brush, with the goal of driving large number of big mammals into narrow lanes, water, cliffs, valleys nets or corrals. For such purpose, some natural features of the landscape have been used by hunters, such as headcuts in arroyos, parabolic sand dunes, and narrow, deep, steep-sided valleys or corridors (Frison, 1998: 14580). When such natural features of the landscapes were not available or insufficient, structural modifications of the landscapes have been created and maintained by hunters, often over long periods of time. For instance, this includes terrestrial fences - made either of stones, brush or wood - placed to facilitate the driving of large herbivores into corrals for killing (Smith, 2011).

Of course, the characteristics of a drive depend on the ecosystem in which it is built and also on the animal species that are hunted. However archaeological evidence show that this hunting strategy was used widespread. Indeed, traps of this general type for hunting wild game are widely known around the world, from North America (Frison, 1998; Hockett, B. et al., 2012; O'Shea et al., 2013) to the Artic, Scandinavia, Tibet (Fox and Dorji, 2009), and the Levant (Rosen \& Perevolotsky, 1998; BarOz et al., 2011; Betts and Burke, 2015).

\section{Preferred Landscapes and Animal Species}

The analysis of the archaeological evidence provided by the numerous worldwide presence of driving leads us to highlight the main features of this hunting strategy.

First, driving has been used in various climates, from the Arctic to the Arabian desert, and in most cases the driving structures were implemented in plains or flat landscapes, i.e. in open terrain with sparse vegetation cover (e.g. in the Great Basin). However, this common feature is not exclusive. Indeed, drive structures also exist in mountainous landscapes (e.g. the Rocky Mountains; Buchholtz, 1983; Frison, 2004). Recent discoveries at alpine sites south of the Rocky Mountains National Park have demonstrated that some camp sites and large game drive systems date between 3850 and 3400 B.C. Thus, in addition to using mountain passes for routes of travel, prehistoric people also hunted in the high country where they constructed rock walls to enhance the natural contour of the slopes, creating "game drive systems."

Second, driving has been used to hunt various animal species, mainly artiodactyls, but most of them were migratory species. The latter include, for instance, the North American bison, the North

\footnotetext{
${ }^{12}$ Their chronology is debated but some desert kites appear to have functioned as early as the 7 th millennium BC.
} 
American pronghorn, North American caribou and reindeer, the Tibetan antelope, the Persian Gazelle, (...). However, this common feature is not exclusive. Indeed, drive structures have also been used to hunt non migratory species such as the Rocky Mountains bighorn sheep (Ovis canadensis), a species of wild sheep native to North America (Buchholtz, 1983; Frison, 2004), as well as most ${ }^{13}$ deer that are present in all continents (especially America and Eurasia), Dorcas gazelle, Arabian oryx, and Onager.

\section{Near-Eastern Wild Caprines: their Possible Capture in Drive Corral}

The two features previously presented lead us to define what were the favored landscapes and animal species that were concerned by driving. Indeed, it appears that driving was mainly used in steppic environment in order to hunt herds of large herbivores along their migratory roads. However driving structures were also used in mountainous landscapes to hunt non migratory large herbivores. Frison (2004) provided archaeological evidence of trapping bighorn sheep in the Rocky Mountains. Eakin (2005) has documented the existence of bighorn sheep traps in the mountainous Wyoming that were still used by Shoshone groups in the nineteen century. These drives were made of timber and rocks and had a basic $\mathrm{V}$ shape. Constricting wings were leading to a catch pen constructed from logs because of the strength necessary to hold one or two animals before killing. Bones and burned skulls found near these structures have confirmed that they were used to hunt bighorn sheep. One may however wonder why these animals have not been captured and kept in captivity, as it was for the Near-Eastern wild caprines, especially the mouflon (another member of the genus Ovis)? The answer is that although the bighorn sheep (Ovis Canadensis) live in large herds, they do not typically follow a single leader ram, unlike either the mouflon/wild sheep (Ovis orientalis), or the bezoar/wild goat (Capra aegagrus). As highlighted by Price (2002: 23), some behavioral characteristics are considered favorable for the domestication of vertebrate animals. Among the latter, some are about the social structure of animal populations and they include social organization, dominance hierarchy, large gregarious social groups and males affiliated with social group (see also Zeder, 2012). In others words, the key animal behavior attribute is the fixed-membership herd based on a male hierarchy within the herd. It is because they have this attribute that wild sheep, goat and cattle, which were relatively minor hunted resources during the Epipalaeolithic, have been subsequently domesticated while bighorn sheep or Persian gazelles, which were extensively hunted during that period, were never domesticated since they do not have this attribute (Rowley-Conwy and Layton, 2011: 856).

We have thus demonstrated that despite they were non migratory species and they were living in non steppic environments, the Near-Eastern wild caprines (wild goat and wild sheep) could have been hunted and later captured by pre-Neolithic hunters using drive and corralled structures. Such hunt and the capture were even facilitated because these animals are gregarious and highly social. Indeed, they follow the lead of a dominant herd member or all move together, an attribute that hunters have exploited subsequently in order to tame and domesticate these species.

\section{Active versus Passive Forms of Drive Hunting}

Although the function of some drives - the desert kites - has been recently questioned, it is commonly agreed that all these structures were devoted for hunting wild animals (Rosen \& Perevolotsky, 1998). Even though hunting was their function, these structures could be used according to two different methods (Betts and Burke, 2015: 83).

The first one may be called "active form" because the hunters locate animals in the wider landscape and attempt to drive them - by calling and flushing - into the constructed enclosure. It is called an "active form" because when the game is moving unpredictably, hunters need to drive game proactively into traps. If the purpose of the drive is the hunt, then once animals are caught into the enclosure they are culled by hunters concealed outside the corral. Even though some animals escape from the funnel or from the corral, the likelihood success of the hunt can be improved by using some features of the natural landscape. For instance the driving structure can be located near the edges of steep cliffs or near a river or a water pond and then escaping animals would be caught into these "natural" traps. If hunters' purpose is to capture wild animals, the active form of driving presents some major shortcomings. Indeed, this strategy is costly and risky. It is costly because many hunters are required to herd the animals toward the drive; we have to recall that pre-Neolithic hunters were

13 Even though some deer are migratory species, such as, for instance, mule deer and reindeer. 
pedestrians. It is risky because animals are frightened from the beginning to the end of the drive. Thus, most of them can try to escape from the funnel or the corral and then can be injured. Among the latter, young animals and pregnant females are especially vulnerable because they are more likely injured by the rush of the other panicking animals.

Therefore, the second form of drive hunting, called the "passive form" seems more suited for the capture of wild animals. Indeed, drive traps are set along paths or areas which animals habitually frequent. Such methods are commonly employed to hunt animals that have regular migration patterns. However, as previously explained, such method can also be used for the capture of non migratory species (wild sheep, deer). Such hunting strategy is called "passive" because the animals might wander into the funnel unawares. The hunters wait until the animals are within the guiding arms of the trap and then chase them into the enclosure. Near the latter two or three hunters wait in hiding while their fellows attempt to drive the animals into the catch pen. As soon as they manage to do this, those who are waiting in ambush hasten to barricade the entrance of the corral with stones, wood and brush, and the animals are imprisoned into the pen. In other words, the passive form of driving provides a less costly and less risky strategy to capture wild animals.

\section{Baiting and the Passive Form of Drive Hunting}

Some improvements of this passive form of driving are possible. Indeed, since animals are going by themselves into the trap, one may wonder how a large number of animals can be caught. Two non exclusive improvement are possible. The first one consists in building large drive structures, i.e. with an important width between the two arms of the funnel. Moreover, several drive structures can be built side by side, extending greatly the effectiveness of the trap. This fits well with the suggestion that the large chained, star-shaped kites of eastern Jordan ${ }^{14}$ formed a passive system of trapping, designed to obtain optimum benefit from the seasonal movement of gazelle out of the deep steppe (Betts and Burke, 2015). The second one is to use a bait in order to attract the animals into the trap. For instance, Nadel et al. (2010), have demonstrated that in the Negev, the head of the desert kites were built in shallow wadi beds. In such an arid environment, it is sure that the access to water has attracted wild game, either migrating or not. We may surmise that some other baits have been used to attract game. For instance it is well known that ungulates - especially those living in alpine environment - are strongly attracted by mineral licks, particularly by salt. In fact many animals regularly visit mineral licks to consume clay, supplementing their diet with nutrients and minerals. Of course mineral licks can be naturally occurring or artificially, the latter being a form of baiting. Finally we may also assume that some plants have been cultivated around and especially inside the driving structure, i.e. into the funnel and the corral. These cultivation acted like what we currently call "food plots", a strategy widely used by modern hunters in order to attract wild game in specific location in order to reduce hunters' effort, to allow selective hunting and also to increase the return of the hunt.

\section{CONCLUSION}

According to niche construction theory, pre-Neolithic foragers have managed the wild resources of the environment where they were living in. In foragers' societies hunting occupies a central place for biological, social and cosmological reasons. Therefore hunters have developed hunting strategies aiming to increase preys availability. We have claimed that baiting, i.e. the use of food to attract wild animals - e.g. Near-Eastern wild caprines - could have been one of these strategies. We have demonstrated that baiting was feasible for pre-Neolithic foragers and that it was necessary for settled hunters facing a sink-source problem related to game procurement. Moreover, several reasons - e.g. milk exploitation, animal translocation - might have motivated these hunters to capture wild animals alive. For such purpose baiting seems to have been a component of the best-suited strategy, i.e. a passive form of drive hunting. Therefore baiting has facilitated the management of wild animals, leading later to their domestication, although it was initially designed either to increase prey availability or to ease the capture of wild animals. Baiting is thus clearly a mechanism which has led inadvertently to animal domestication.

\footnotetext{
${ }^{14}$ The largest number of these structures is recorded in the deserts of eastern Jordan where they often form chains of up to $60 \mathrm{~km}$ long.
} 
In addition to this conclusion we may even surmise another result. Indeed, it is often claimed (as we did in section 3) that for the domestication of cereals, it is the change of the harvest technique (from the basket swinging to the sickle) that has led to the unconscious selection of the non shattering seeds. We may provide an alternative explanation. Since initial cultivation of cereals had a very low productivity (Bowles, 2011; Berbesque et al., 2014), it is less likely that the first "cultivators" have devoted such production to sustain their own diet, because it was a risky strategy. However, if such cultivation was dedicated to attract wild game in specific locations, i.e. was used as bait in food plots, its low productivity was no more a problem. Moreover, the cultivators were not very vigilant about the ripening of the cereals they grew in their food plots. In fact they just had to gather enough seeds in order to be able to sow later another food plot. They did it lately, after all the cereals had ripened. Thus, for all the ears without seeds retention, only the stalks were remaining and their harvest was useless. In other words, these first cultivators have harvested mainly (and perhaps exclusively) and inadvertently non shattering seeds, i.e. they may also have contributed to the domestication of cereals.

\section{REFERENCES}

Atici L. (2009), Implications of Age Structures for Epipaleolithic Hunting Strategies in the Western Taurus Mountains, Southwest Turkey, Anthropozoologica 44(1): 13-39.

Bar-Yosef, O., and R.H. Meadow (1995), The origins of agriculture in the Near East. In Last hunters, first farmers: new perspectives on the prehistoric transition to agriculture. T. D. Price and A.-B. Gebauer, eds. Pp. 39-94. Santa Fe, NM: School of American Research Press.

Bar-Oz, G., M. Zeder, and F. Hole (2011), Role of mass-kill hunting strategies in the extirpation of Persian gazelle (Gazella subgutturosa) in the northern Levant, PNAS 108(8): 7345-7350.

Berbesque, J. C., Marlowe, F. W., Shaw, P., and Thompson, P. (2014), Hunter-Gatherers Have Less Famine than Agriculturalists. Biology Letters 10: 20130853. URL: http://dx.doi.org/ 10.1098/ rsbl.2013.0853.

Betts, A. and D. Burke (2015), Desert kites in Jordan - a new appraisal, Arabian archaeology and epigraphy, 26: 74-94.

Boivin, N.L. (2016), Ecological consequences of human niche construction: Examining long-term anthropogenic shaping of global species distributions, PNAS 113(23): 6388-6396.

Bowles, S. (2011), Cultivation of Cereals by the First Farmers Was not More Productive than Foraging. PNAS 108(12): 4760-4765.

Buchholtz, C. (1983), Rocky Mountain National Park: A History — Colorado Associated University Press, Boulder, CO.

Clottes, J. and D. Lewis-Williams (1998), The Shamans of Prehistory. New York: Harry N. Abrams, Inc.

Cordain, L. et al. (2000), Plant-animal subsistence ratios and macronutrient energy estimations in worldwide hunter-gatherer diets, American Journal of Clinical Nutrition 71: 682-692.

Delibes, M. et al. (2001), Effects of an Attractive Sink Leading into Maladaptive Habitat Selection, The American Naturalist 158(3): 277-285.

Eakin, D.H. (2005), Evidence for Shoshonean bighorn sheep trapping and Early historic occupation in the Absaroka Moutains of northwest Wyoming. University of Wyoming National Park service research center annual report: vol 29, article 36. Available at: http://repository.uwyo.edu /uwnpsrc_reports/vol29/iss1/36/

Flannery, K.V., (1969), Origin and Ecological Effect of Early Domestication in Iran and the Near East, in The Domestication and Exploitation of Plants and Animals, Ucko, P.J., and Dimbleby, G. W. (Eds.). Duckworth: London, 73-100.

Fox, J. \& Dorji, T. (2009), Traditional Hunting of Tibetan Antelope, Its Relation to Antelope Migration, and Its Rapid Transformation in the Western Chang Tang Nature Reserve. Arctic, Antarctic, and Alpine Research 41(2): 204-211.

Frison, G.C. (1998), Paleoindian large mammal hunters on the plains of North America, PNAS 95: 14576-14583.

Frison, G. (2004), Survival by Hunting. Prehistoric Human Predators and Animal Prey. University of California Press, Berkeley, CA.

Fuller, D.Q., G. Willcox \& R.G. Allaby (2011), Cultivation and domestication had multiple origins: arguments against the core area hypothesis for the origins of agriculture in the Near East, World Archaeology 43(4): 628-652. 
Gremillion, K.J., L. Barton and D.R. Piperno (2014), Particularism and the retreat from theory in the archaeology of agricultural origins, PNAS 111(17): 6171-6177.

Harlan, J.R. (1992), Crops and Man, Madison (WI), American Society of Agronomy.

Hawkes, K. (1991), Showing off tests of an hypothesis about men's foraging goals, Ethology and Sociobiology 12(1): 29-54.

Hawkes, K. (2001), Is Meat the Hunter's Property? Big Game, Ownership, and Explanations of Hunting and Sharing, In Stanford and Bunn (ed.) Meat-Eating and Human Evolution. Oxford: Oxford University Press, 219-236.

Helmer D. \& Vigne J.-D. (2007), Was milk a "secondary product" in the Old World Neolithisation process? Its role in the domestication of cattle, sheep and goats. Anthropozoologica 42(2): 9-40.

Hockett, B. et al. (2012), Large-scale trapping features from the Great Basin, USA: The significance of leadership and communal gatherings in ancient foraging societies, Quaternary International $\mathrm{xxx}$ : 1-15.

Kelly, R.L. (1995), The Foraging Spectrum: Diversity in Hunter-Gatherer Lifeways, Washington and London: Smithsonian Institution Press.

Larson, G. et al., (2014), Current Perspectives and the Future of Domestication Studies, PNAS 111(17): 6139-6146.

Larson, G. and D.Q. Fuller (2014), The Evolution of Animal Domestication, Annual Review of Ecology, Evolution and Systematics 45: 115-36.

Leopold, A. (1933), Game Management. Charles Scribner and Sons, New York, NY.

Linares, O. F. (1976), "Garden Hunting" in the American Tropics, Human Ecology 4(4): 331-349.

Marciniak, A. (2011), The Secondary Products Revolution: Empirical Evidence and its Current Zooarchaeological Critique, Journal of World Prehistory 24: 117-130.

McClure, S.B. (2015), The pastoral effect. Niche construction, domestic animals, and the spread of farming in Europe, Current Anthropology 56(6) : 901-910.

Nadel, D. et al. (2010), Walls, ramps and pits: the construction of the Samar Desert kites, southern Negev, Israel. Antiquity 84 : 976-992.

Naderi, S., et al. (2008), The goat domestication process inferred from large-scale mitochondrial DNA analysis of wild and domestic individuals, PNAS 105(46): 17659-17664.

Odling-Smee F.J., Laland K.N., Feldman, W. (2003), Niche construction. Monographs in Population Biology 37. Princeton: Princeton University Press.

O'Shea, J., A.K. Lemke and R.G. Reynolds (2013), "Nobody knows the way of the Caribou": Rangifer hunting at $45^{\circ}$ North latitude, Quaternary International 297: 36-44.

Powell, R.A. \& G. Proulx (2003), Trapping and marking terrestrials mammals for research: integrating ethics, performance criteria, techniques, and common sense, ILAR Journal 44(4): 259-276.

Price, E.O. (2002), Animal Domestication and Behavior. Wallingford: CABI Publishing.

Price, T.D. and O. Bar-Yosef (2011), The Origins of Agriculture: New Data, New Ideas. An Introduction to Supplement 4. Current Anthropology, Vol. 52, No. S4, The Origins of Agriculture: New Data, New Ideas: S163-S174.

Pryor, F. (2004), From Foraging to Farming: The So-Called "Neolithic Revolution", in A.J. Field (ed.), Research in Economic History, Vol. 22: 1-41, Greenwich (CT), JAI Press.

Putman, R.J., Staines, B.W. (2004), Supplementary winter feeding of wild red deer Cervus elaphus in Europe and North America: justifications, feeding practice and effectiveness. Mammal Review 34: $285-306$.

Rosen, B. \& Perevolotsky, A. (1998), The function of 'desert kites' - hunting or livestock husbandry? Paléorient 24(1): 107-111.

Rowley-Conwy, P. and R. Layton (2011), Foraging and farming as niche construction: stable and unstable adaptations, Philosophical transactions of the Royal Society B 366: 849-862.

Savolainen, P. et al. (2002), Genetic Evidence for an East Asian Origin of Domestic Dogs, Science 298(5598): 1610-3.

Sherratt A. (1983), The secondary exploitation of animals in the Old World. World Archaeology 15: 90-104. 
Smith, B.D. (1995), The emergence of agriculture, Scientific American Library: New York.

Smith, B.D. (2001), Low-Level Food Production. Journal of Archaeological Research 9: 1-43.

Smith, B.D. (2007), Niche Construction and the Behavioral Context of Plant and Animal Domestication, Evolutionary Anthropology 16: 188-199.

Smith, B.D. (2009), Resource Resilience, Human Niche Construction, and the Long-Term Sustainability of Pre-Columbian Subsistence Economies in the Mississippi River Valley Corridor, Journal of Ethnobiology 29(2):167-183.

Smith, B.D. (2011), General patterns of niche construction and the management of "wild" plant and animal resources by small-scale pre-industrial societies. Philosophical Transactions of the Royal Society B 366: 836-848.

Smith, B.D. (2012), A Cultural Niche Construction Theory of Initial Domestication, Theoretical Biology 6: 260-271.

Smith, B.D. (2015), A comparison of niche construction theory and diet breadth models as explanatory frameworks for the initial domestication of plants and animals. Journal of Archaeological Research 23: 215-262.

Smith, B.D. and M.A. Zeder (2013), The onset of the Anthropocene, Anthropocene 4: 8-13.

Stahl, P.W. (2014), Garden Hunting, in Encyclopaedia of Global Archaeology, 2945-2952, edited by C. Smith. Springer: New York.

Vigne, J.D. (2011), The origins of animal domestication and husbandry: a major change in the history of humanity and the biosphere. Comptes Rendus de l'Académie des Sciences, Biologie. 334(3): $171-181$.

Vigne, J.D., I. Carrère, F. Briois, and J. Guilaine (2011), The Early Process of Mammal Domestication in the Near East. New Evidence from the Pre-Neolithic and Pre-Pottery Neolithic in Cyprus, Current Anthropology Volume 52, Supplement 4, S255-S271.

Wilson, C.J., A.M. Britton and R.G. Symes (2009), An Assessment of agricultural damage caused by red deer (Cervus elaphus L.) and fallow deer (Dama dama L.) in southwest England, Wildl. Biol. Pract., 5(2): 104-114. DOI:10.2461/wbp.2009.5.11

Winterhalder, B. and D.J. Kennett (2006), Behavioral ecology and the transition from hunting and gathering to agriculture, in D.J. Kennett and B. Winterhalder (eds.), Behavioral Ecology and the Transition to Agriculture, Berkeley: University of California Press, pp. 1-21.

Zeder, M.A. (2005), New perspectives on livestock domestication in the Fertile Crescent as viewed from the Zagros Mountains. In The first steps of animal domestication: new archaeobiological approaches. J-D. Vigne, J. Peters, and D. Helmer, eds, 125-147. Oxford: Oxbow.

Zeder, M.A. (2008), Domestication and early agriculture in the Mediterranean Basin: Origins, diffusion, and impact, PNAS 105(33): 11597-11604.

Zeder, M.A. (2009), The Neolithic Macro-(R)evolution: Macroevolutionary Theory and the Study of Culture Change, Journal of Archaeological Research 17: 1-63.

Zeder, M.A. (2011), The Origins of Agriculture in the Near East, Current Anthropology, Vol. 52, No. S4, The Origins of Agriculture: New Data, New Ideas: S221-S235.

Zeder, M.A. (2012), The domestication of animals, Journal of Anthropological Research 68(2): 161190.

Zeder, M.A. (2015), Core questions in domestication research, PNAS 112(11): 3191-3198. 